\title{
Changing the Mindset of Engineering Educators to Teach Design Studios
}

\author{
Yasemin Tekmen-Araci, Beata Francis, Roger Hadgraft, Ian Zucker, Justine Lawson and Robert \\ Jarman \\ University of Technology Sydney \\ Corresponding author: Yasemin.TekmenAraci@uts.edu.au
}

\section{Introduction}

In our educational system the most important part is to question the purpose of education: Is it to deliver knowledge, to enhance curiosity, to enable students to solve problems or to equip students with lifelong learning skills? (Sims, 2011).

The University of Technology Sydney (UTS) is a polytechnic university and as such aims 'to be a world-leading university of technology' (UTS 2027 Strategy). UTS recognises the value of a collaborative and creative workforce, which includes students as partners together with the wider community on a professional development path where students gain industrial and professional experience concurrently with classroom work. In the Faculty of Engineering and Information Technology (FEIT), the move to become collaborative is marked by an initiative to shift the mindsets of academic teaching staff.

FEIT at UTS recruited and established a 'Learning and Teaching Design' team in 2016. One of the primary aims of this learning design team was to change the mindset of engineering academics and specifically to orient and substantively engage, write and deliver a curriculum that produced More Innovative Design-Abled Students and Staff (the MIDAS project).

MIDAS Summer Studios were a response to industry demands for graduates who are able to respond more innovatively to the challenges in our world. MIDAS is a "cultural transformation project that is reinventing curricula, learning and teaching practices, through student and stakeholder engagement, to prepare graduates for the new world of work in the 21 st century, requiring a focus on innovative design practices" (Hadgraft et al., 2017). The

MIDAS Summer Studios works strategically to shift the culture of engineering education and aims to revolutionise how students learn engineering and information technology at UTS. In matters of teaching and learning, they rely on the principles of inspired pedagogy to inform teaching and learning practices.

\section{MIDAS Summer Studios}

In an effort to experience what an 'inspiring' pedagogy might look like, in February 2018, a set of short, intensive, summer school offerings were designed and delivered. MIDAS Summer Studios draw inspiration from the disciplinary practice of studio learning from other design disciplines such as architecture and industrial design. The Summer Studio offerings sought to reproduce what it means to be in engineering practice: to engage in open-ended and often ill-defined projects and briefs; students are asked to work collaboratively and intensively to present their project deliverables.

MIDAS is best captured in the MIDAS Summer Studios. These Summer Studios were developed to create the next generation engineering and IT programs at UTS using a sequence of studios in every program. Learning to teach in studio environments is as much a re-education for staff as it 
is for students. Both groups are discovering that the higher education learning experience can be more active and student-oriented than imagined previously.

MIDAS Summer Studios were introduced in the Summer 2018 teaching term as an elective subject. They were open for enrolment to students from all levels and from all faculties. The studios were high energy, open-ended, collaborative and project-based learning environments. Each studio delivered a different focus based on real-world engineering and IT problems. It was scheduled to be completed within six weeks (a compressed schedule compared to a regular semester of $12-$ 14 weeks).

Eighteen teams of academics volunteered to conduct a studio in a range of topic areas.

In 2018, 160 students enrolled in 10 studios broadly clustered into the following three areas:

- Meeting future human needs in cities;

- Data science and artificial intelligence; and

- Design and build amazing devices including robots.

Facilitated by a mixture of academic, industry and community partners, each studio sought to bring real-world problems, enable opportunities for students to explore and experiment with available resources whilst considering their real-world applications and implications. The MIDAS Summer Studio consisted of a single assessment, the ePortfolio, graded on Pass or Fail basis. This approach to assessment is intended to be formative, and to encourage constructive and continuous reciprocal feedback. The single assessment task is a portfolio of evidence to show the progress individual students made in the six weeks. An underlining aim of the portfolio is for students to demonstrate that they are developing professional capabilities and technical rationality. A formal technical report is usually a part of the final portfolio.

At the core of the MIDAS Summer Studio is the design thinking process. "Design thinking provides a set of creative methodologies for solving problems and generating ideas that is based on building up solutions, rather than starting with the answer" (Sims, 2011, p. 12). The subject learning outcomes were modelled on FEIT's graduate attributes-problem definition, use a design process, apply modelling skills, collaborate and communicate, and self-management (Hadgraft et al., 2018).

In order to confirm that each of the studios and their studio leaders delivered a calibrated student learning experience (e.g. design, delivery, process and assessment), a series of training workshops were developed to ensure that the language used by studio facilitators remained consistent. These workshops were conducted by the Teaching and Learning Design Team. Studio leaders were required to prepare students to understand how to apply the design thinking approach in the context of their studio. Several facilitated training workshops were run covering topics such as design thinking, active listening, posing powerful questions, and assessing portfolio.

The training sessions provide specific examples and a variety of educational tools to equip facilitators with a mindset and the confidence to facilitate a meaningful and impactful studio experience. During these workshops, participants were encouraged to adopt the following ten values and principles, which were adapted from existing scholarship on engineering education:

1. Injecting beauty, joy and love

2. Connect hearts and minds

3. Notice, Listen and Question

4. Manage polarities

5. Embrace vulnerability 
6. Design 'free range' education

7. Create the Care effect

8. Empathise with students

9. Name one's deep assumptions

10. Make small bets.

This study reports how these values have been effective in transforming engineering education in one university in Australia.

\section{Background: Changing the Mindset and Skill Set of the Educators}

Changing the mindset and the skill set of the instructors is no easy task. Many researchers indicate that instructors' teaching practices are shaped by their beliefs. This change process involves encouraging educators to develop new teaching methods (Henderson, Beach, \& Finkelstein, 2011). For changing culture, participants need to change their "modes of activities", "languages" and "social relationships". Change in any of these aspects will have an impact on other aspects of the local culture (Kemmis \& McTaggart, 1988).

Henderson et al. (2011) argues that facilitating change in undergraduate STEM (Science, Technology, Engineering and Mathematics) education requires long-term interventions and must involve changing the beliefs of individuals. However, many scholars think that 'beliefs' are difficult to change. Indeed, a relationship between beliefs and actions exists (Richardson, 1996). Kelchtermans (2009) claims that a teacher's perceptions change alongside the local cultural, social and environmental structures. Therefore, to make change in culture, deeply held beliefs need to change first (Quinlan, 2002).

Moore et al. (2015) explain the importance of engineering educators' beliefs and pedagogical approaches in shaping their teaching style, and how student learning is connected to educators' teaching. However, this is not easy. Any kind of change in higher education cannot be done without accounting for the deeply entrenched and well-established structures and traditions that are already in place (Berglund et al., 2011). Some believe that change happens very slowly in academia, especially in the engineering sciences (Pons, 2016) because engineering is a particularly conservative discipline (Daly et al., 2014).

Psychologists have discovered that our minds are ruled by two different systems-the rational mind and the emotional mind. The rational mind wants to change something at work; the emotional mind loves the comfort of the existing routine (Heath \& Heath, 2010).

Heath and Heath (2010) listed many causes to resist change, many of them regularly observed in academia:

- "People don't see the need to change"

- "We've never done it like that before" approach

- "People simply aren't motivated to change"

- "I'll change tomorrow" procrastination

- "It will never work" misbelief

- "I know what I should be doing, but I'm not doing it" impassiveness

- "You don't know my people. They absolutely hate change" perspective

- "It's just too much" thought

- "Everyone seems to agree that we need to change, but nothing's happening" resistance. 
Tekmen Araci (2018) conducted her doctoral research about enhancing creativity in engineering education and argues that if engineering instructors do not change their approach and the discipline does not cooperate, enhancing creativity in engineering education is difficult. Following Heath and Heath (2010) we acknowledge that championing change in a large organisational structure like a university will come with an array of challenges, which include academic staff themselves. By drawing attention to the relationship between 'change' and 'beliefs' - it is possible to see what kinds of challenges (and resistance) will be made apparent. In order to change engineering education, it is the educational researchers, the curriculum developers and designers and engineering academics who all need to work collaboratively to change the curriculum but also change deeply held beliefs (Tekmen Araci, 2018).

Henderson et al. (2011) reviewed almost two hundred journal articles about change strategies in STEM education and they claim that effective change strategy starts with finding ways of changing the beliefs of the individuals involved. "For things to change, somebody somewhere has to start acting differently" (Heath \& Heath, 2010, p. 259). Adopting this method, the MIDAS team is working to change beliefs of engineering educators whilst simultaneously seeking to change the curriculum.

\section{MIDAS Summer Studio Values}

As noted earlier, the MIDAS Summer Studios aim to enhance the educational experience in FEIT. They aim to sustain more innovative design-abled students and staff. For MIDAS Summer Studios, collaboration is the key. This is because by taking collective responsibility for both the successes and setbacks, the MIDAS Summer studios aim to cultivate and harness impactful relationships to build a groundswell of positive change within FEIT, ushering in an era of exceptional teaching and learning. The Teaching and Learning Design team established and continues to maintain a tapestry of relationships between students, staff and industry partners, to design, develop, and deliver as well as to regularly evaluate the effectiveness and sustainability of a co-designed curriculum. Through these relationships, the set of values, are discussed in more detail below.

The values explained in this paper were curated and adopted from literature on change leadership. In particular the team benefited from the author, researcher and Change Masters coach Dave Goldberg, who has combined fifty years of experiences in higher education and transformation of teaching and learning, especially with respect to engineering education. Goldberg (2017-2018) has been pivotal in coaching the Teaching and Learning Design team in teaching and learning differently through his ChangeMasters ${ }^{\mathrm{TM}}$ coaching and through deeper conversations with our academics about impacts of the MIDAS Summer Studio experience. We have organically identified 10 different values (listed above) that guide our work in transforming engineering education and supporting inspirational pedagogy:

\section{Inject Beauty, Joy and Love}

Engineering and IT teaching can be very technical. Dave Goldberg encourages us to think about beauty, joy and love. We learn better when we connect past experiences to current ones. Art and beauty can create profound shifts in perspective. We need to think where we might inject beauty. Pugh and Girod (2007) present a view of science education from the perspective of art and aesthetics. They (2007) present three ideas that influence our language for injecting beauty, joy and love into engineering and information technology education. 
They are:

1. We learn better by experiencing things

2. We learn better when we connect new experiences to our past experiences

3. The experience of art can produce profound shifts in perspective.

MIDAS Summer Studios build on this work and encourage educators to find joy, love and beauty in their teaching and suggests that educators share this with their students.

\section{Connect Hearts and Minds}

Engaged learning occurs when cognition, affect and action are connected. David Goldberg suggests moving from thinking only from "brain" to "heart and mind". We often focus overly on the thinking and understanding required in our subjects. Students are more than just "a-brain-ona-stick". We should stop seeing our students just "brains", but "heart and minds" as well. They are people and they have emotions. We need to empathise. Therefore, educators should look to inspire their students with strong positive emotions in their subjects. In order to do this, academics not only need to think with their brain but also they need to think from their heart as well.

\section{Notice, Listen, Question (NLQ)}

More than active listening, NLQ is a coaching skill we can practise and teach our students. It enables genuine curiosity in others and opens doors for deeper understanding of others and ourselves. Notice language, emotion and body. The range of what we think and do is limited by what we fail to notice. Because we fail to notice what we fail to notice, there is little we can do to change until we notice how failing to notice shapes our thoughts (Goldberg, 2018).

Goldberg (2018) suggests we listen on two levels:

Level 1: Internal listening. You seem like you are listening to the person talking; however, in that instant you are actually thinking about yourself. You think about "What does this mean to me?"

Level 2: In this type of listening, focus is on the other person. While listening to the person talk, you ask questions. You think about "What does this mean to this person?"

Educators and students need to listen on the second level, which helps to empathise with people and to truly understand the needs of the person to whom we are listening. Adams (2004) believes changing the questions we ask will change our lives and, in turn, this will transform our attitudes and actions. Asking powerful 'what' questions is a short-cut to exploring thoughts and feelings more easily (Adams, 2004). By noticing our surroundings and listening to each other at a deeper level and to ask the right questions, we are well positioned to embrace transformation.

\section{Manage Polarities}

There is good news and there is bad news. The bad news is there are unsolvable problems to be solved, the ones we cannot solve with existing resources. The good news is we can improve our skills to identify the unsolvable problems and manage them well. Johnson (1996) asks "What do you want to do, breathe in or breathe out'?" By answering this in an either/or way, he insists that we are already privileging one over the other. Rather, Johnson (1996) points out: we need both. Therefore, most situations are not 'either/or' but 'yes/and'. Two opposites cannot function well independently of each other; rather they are polarities, to be managed. We often hear research is more important than teaching and learning. By rejecting the premise that an answer must be 'either/or', we propose 'yes/and' solutions. Our research agendas can inform the subject matter we teach. Our teaching practices can inform our research. 


\section{Be Vulnerable}

Hillman (2013) highlights what the 'imposter syndrome' is and how people are undermined by their own fear of believing that they are not qualified to do the job they are appointed to do. Brown (2012) argues for letting go of shame and to let our authentic selves be seen. Further, we need to believe 'we are enough'. In turn, this means that we are allowing ourselves the opportunity to be authentic and vulnerable. Based on Brene Brown's (2010) discussion of vulnerability, we should be able to say 'I don't know' rather than expecting to have the answer to every student question. In the MIDAS Summer Studios, staff are encouraged to be human; it is okay to not always be right, and most importantly it is okay to need others, because, as Brown (2010) argues, vulnerability is the first place of creativity, innovation and change.

\section{Design 'Free Range' Education}

Some of our teaching practices and assessment mirror caged hens. Approaching students like they are caged hens, force-feeding them, regulating the conditions, and prescribing what they should do in every step, is inauthentic and portentously dangerous.

If we extend the metaphor, a common practice found among those who are caged are exam-based assessments. MIDAS is about transforming assessment, so that students 'learn to remember' rather than cram information for an exam. Therefore, MIDAS Summer Studios allow students to be more 'free range' in their learning.

\section{Create the 'Care Effect'}

In the MIDAS Summer Studios, we ask how might we all create a feeling that leaves you feeling better, lifted and noticed with students and with each other? How can we project our own enthusiasm for our discipline to students? MIDAS Summer Studio educators are encouraged to welcome their students into their studio, to establish connection and trust among the students and facilitators and to project their enthusiasm. "Peer interactions and casual conversations between students and tutors" are part of a studio (Pollock et al., 2015), and they are only achievable by mutual trust. This starts with creating the Fiji care effect in class: creating a welcoming environment.

\section{Empathise with Students}

When designing, reviewing, teaching, and assessing, we should think about the student experience. Better still, ask the students. Our work as educators is both to lead and to be in the service of students. Our work is for students. So we need to understand and care for them deeply. This is a natural consequence of the care effect.

Students tell us they are more eager to come to class and participate when they feel a sense of belonging. Students do not enrol to the studio unit with a clean slate. They arrive with a whole host of prior experiences, skills and ideas. It is worthwhile to find out what students have experienced and what they know and build on these existing skills, experiences and knowledges. MIDAS Summer Studio facilitators should empathise with their students.

\section{Know Your Deep Assumptions}

When you feel strongly about something, ask yourself why? What is the attachment? What do you fear of letting go? Know that deep assumptions underpin all of our actions. Match your deeper 
assumptions with those of others and heighten awareness to better identify points of potential conflict. MIDAS Summer Studios suggest helping students to understand their own assumptions about learning. Immersing students in a new environment where learning can be shaped by each student is a new experience for many. Students must be reminded that they are driving their own education and they need to set aside their previous assumptions such as that learning happens for exams and little of it is useful outside of the university.

\section{Make Small Bets}

Small changes can make big impacts. Do not wait for everything to 'fall into place'. What is one small change you can make today to discover, test and improve new ideas? Small changes enable greater flexibility to reach your goals. Sims (2011) explains what small bets are all about: in order to explore the possibilities for getting great outcomes we need to use little bets and some creative methods. Little bets are the actions taken to discover, test, and develop ideas that are achievable and affordable. They begin as creative possibilities that get iterated and refined over time, and they are particularly valuable when trying to navigate amid uncertainty, create something new, or attend to open-ended problems. When we can't know what's going to happen, little bets help us learn about the factors that can't be understood beforehand (Sims, 2011, p. 8).

Sims (2011) gives many examples from industry, such as Hewlett-Packard, the Gates Foundation, and Google, which did not know they would be big companies before when they started with little bets.

Fundamental to the little bets are

- "Experiment": It is a learning -by- doing approach. If you fail, you learn more quickly.

- "Play": A playful and humorous approach allows incubation of new and creative ideas.

- "Immerse": Collect different fresh ideas and try to understand the motivation of people, get deeper understanding about your surroundings.

- "Define": Before starting to solve the problems define them.

- "Reorient": Be flexible about changing and enlarging your purpose.

- "Iterate": "Repeat, refine and test frequently" for gaining better insight (Sims, 2011, pp. 13-14).

"A long journey starts with a single step [...] The first thing to do is to recognise and celebrate that first step" (Heath \& Heath, 2010, p. 250). We are aware that change does not happen quickly; therefore, it is suggested making small bets first, which must begin with an action. Where someone is keen to do something differently, we clear the roadblocks and let them get on with it. Not everything has to be lined up and ready to go.

\section{Conclusion}

This paper reports on the MIDAS Summer Studio values and principles and how these values are changing engineering and IT education by changing the mindset of engineering educators in design-led studio learning.

The values and principles presented in this paper are gathered in order to inspire educators in their own teaching methods, to create 'a-ha' moments that change mindsets about teaching and learning. There is a complex relationship between language and culture that we must be willing to pay attention to (Benitez-Burraco, 2017). We believe that when you change the words people use to describe their experiences, people will think differently and behave differently. Soon a new culture emerges and becomes stronger as we adopt new cultural practices. In the context of higher 
education, many people belong to the 'old' ways of being and doing things. Now is the time to try new behaviours.

FEIT's MIDAS Summer Studio project has organically developed a language that shifts the thinking of academics and this shift has led to new behaviours (in learning and teaching) that attracts others. MIDAS Summer Studio values providing inspiration for new learning and teaching practices at FEIT.

\section{References}

Adams, M. (2004). Change your questions: Change your life to radically transform attitudes, actions and results.

Benítez-Burraco, A. (2017). How the language we speak affects the way we think. Psychology Today. https://www.psychologytoday.com/blog/the-biolinguistic-turn/201702/how-thelanguage-we-speak-affects-the-way-we-think.

Berglund, A., Klasen, I., Hanson, M., \& Grimheden, M. (2011). Changing mindsets: Improving creativity and innovation in engineering education. In Paper presented at the International Conference on Engineering and Product Design Education, London, UK.

Big Beacon. (2014). 8 Steps to a whole new engineer. Retrieved from March, 2019, from https://youtu.be/pVRO3nKWdLM.

Brown, B. (2012). TED talk: Listening to shame. https://www.ted.com/talks/brene_brown_listening_to_shame?utm_campaign=tedsprea d\&utm_medium=referral\&utm_source=tedcomshare.

Brown, B. (2010). TED talk: the power of vulnerability. https://www.ted.com/talks/brene_brown_on_vulnerability?language=en\&utm_ca mpaign=tedspread\&utm_medium=referral\&utm_source=tedcomshare.

Daly, S. R., Mosyjowski, E. A., \& Seifert, C. M. (2014). Teaching creativity in engineering courses. Journal of Engineering Education, 103(3), 417-449. https://doi.org/10.1002/jee.20048 .

Dweck, C. (2006). Mindset the new psychology if success: How can learn to fulfil our potential. NY: Penguin Random House.

Goldberg, D. E. (2018). ThreeJoyAssociates Inc. 2017-2018.

Hadgraft, R., et al. (2017). Curriculum transformation with students as partners. In D. I. Nazmul Huda, N. Tse, \& G. Town (Eds.), Proceedings of the 28th Annual Conference of the Australasian Association for Engineering Education (AAEE 2017) (pp. 800-808). Sydney: Macquarie University.

Hadgraft, R., Francis, B., Lawson, J., Jarman, R., \& Tekmen-Araci, Y. (2018). Summer studiosLessons from a 'small bet' in student-led learning. In 46th SEFI Annual Conference "Creativity, Innovation and Entrepreneurship for Engineering Education Excellence", Copenhagen, Denmark, September 2018 . 
Heath, C. \& Heath, D. (2010). Switch: How to change things when change is hard. NY: Broadway Books.

Henderson, C., Beach, A., \& Finkelstein, N. (2011). Facilitating change in undergraduate STEM instructional practices: An analytic review of the literature. Journal of Research in Science Teaching, 48(9), 952-984.

Hillman, H. (2013). The impostor syndrome: Becoming an authentic leader.

Johnson, B. (1996). Polarity management: Identifying and managing unsolvable problems.

Kelchtermans, G. (2009). Who I am in How I Teach is the message: Self-understanding, vulnerability and reflection. Teachers and Teaching: Theory and Practice, 15(2), 257-272.

Kemmis, S., \& McTaggart, R. (1988). The action research planner. Victoria: Deakin University. Kotter, J. P. (1996). Leading change. Boston: Harvard Business School Press.

Law of Attraction Central. (2019). Retrieved January 2019, from http://www.lawofattractioncentral.net/greatest-obstacle/

Moore, T. J., Guzey, S. S., Roehrig, G. H., Stohlmann, M., Sun Park, M., Rae Kim, Y., et al. (2015). Changes in faculty members' instructional beliefs while implementing model-eliciting activities. Journal of Engineering Education, 104(3), 279-302. https://doi.org/10.1002/jee.20081

Pollock, V. L., Alden, S., Jones, C., \& Wilkinson, B. (2015). Open studios is the beginning of a conversation: Creating critical and reflective learners through innovative feedback and assessment in Fine Art. Art, Design \& Communication in Higher Education, 14(1), 39-56.

Pons, D. (2016). Relative importance of professional practice and engineering management competencies. European Journal of Engineering Education, 41(5), 530547. https://doi.org/10.1080/03043797.2015.1095164.

Pugh, K., \& Girod. (2007). Science, art, and experience: Constructing a science pedagogy. From Dewey's aesthetics. Journal of Science Teacher Education, 18, 9-27. https://doi.org/10.1007/s10972006-9029-0.

Quinlan, K. M. (2002). Scholarly dimensions of academics' beliefs about engineering education. Teachers and Teaching: Theory and Practice, 8(1), 41-64.

Richardson, V. (1996). The role of attitudes and beliefs in learning to teach. In I. J. Sikula (Ed.), Handbook of research on teacher education: A project of the association of the teacher educators (2nd ed., pp. 102-119). New York: Macmillan.

Sims, P. (2011). Little bets: How breakthrough ideas emerge from small discoveries. NY: Simon \& Schuster Paperback.

Tekmen Araci, Y. (2018). Exploring ways of enhancing creativity in engineering education to promote innovation: Action research in engineering design. Ph.D. submitted to Swinburne University of Technology, Australia. https:// researchbank.swinburne.edu.au/items/259359f83516-4337-8114-99d3989d3261/1/. 